\title{
Review
}

\section{Molecular mechanisms of hepatic apoptosis}

\author{
K Wang ${ }^{*, 1}$
}

Apoptosis is a prominent feature of liver diseases. Causative factors such as alcohol, viruses, toxic bile acids, fatty acids, drugs, and immune response, can induce apoptotic cell death via membrane receptors and intracellular stress. Apoptotic signaling network, including membrane death receptor-mediated cascade, reactive oxygen species (ROS) generation, endoplasmic reticulum (ER) stress, lysosomal permeabilization, and mitochondrial dysfunction, is intermixed each other, but one mechanism may dominate at a particular stage. Mechanisms of hepatic apoptosis are complicated by multiple signaling pathways. The progression of liver disease is affected by the balance between apoptotic and antiapoptotic capabilities. Therapeutic options of liver injury are impacted by the clear understanding toward mechanisms of hepatic apoptosis.

Cell Death and Disease (2014) 5, e996; doi:10.1038/cddis.2013.499; published online 16 January 2014

Subject Category: Experimental Medicine

Facts

- Apoptosis is a typical pathological feature of liver diseases.

- The severity of hepatic apoptosis is varied due to different etiologic factors.

- There are distinct mechanisms to mediate hepatic apoptosis. One mechanism dominates over others at a particular stage.

- Interventions for hepatic apoptosis alleviate liver injury as demonstrated by pre-clinical models and clinical trials. The regulation of hepatic apoptosis affects the progression of liver diseases.

\section{Open Questions}

- Multiple signaling pathways form a complicated network to modulate the hepatic apoptosis.

- Molecular targets of hepatic apoptosis and the detail of regulatory mechanisms need to be determined.

- Therapeutic options of liver diseases depend on the correct understanding toward mechanisms of hepatic apoptosis.

\section{Introduction of Hepatic Apoptosis}

Liver injury can be caused by different stimuli such as alcohol intake, viral infection, cholestasis, steatosis, drug abuse, and autoimmunity. ${ }^{1-6}$ Genetic variability is interacted with environmental factors, which makes liver damage in a variety of severity. ${ }^{7}$ In the damaged liver, cell death modes include apoptosis, necrosis, necroptosis, and autophagy. These medical terms have clear definitions in pathology. However, different modes of cell death are intermingled as a continuous process during liver injury. Apoptosis and necrosis are two major types of cell death. ${ }^{8}$ They consist in a dynamic spectrum. Apoptosis is an early, chronic, and temperate response subsequent to injury induction, whereas necrosis is an acute and severe reply. Causative factors of liver injury may induce both modes of cell death dependent on the severity of the insult. Apoptotic cells are characterized by energy-dependent biochemical mechanisms and distinct morphological changes. ${ }^{9,10}$ Apoptosis shares common cell death machinery, including death receptor-dependent and mitochondria-dependent pathways. ${ }^{11,12}$ Dysfunction or dysregulation of the apoptotic program is implicated in a variety of congenital anomalies and pathological conditions. ${ }^{13,14}$ Because of differences in etiology, hepatic apoptosis and its pathophysiological role have much discrepancy during liver injury.

\section{Etiology and Mechanisms of Hepatic Apoptosis}

Viruses. Hepatotropic viruses such as hepatitis A virus, hepatitis $E$ virus, cytomegalovirus, herpes simplex virus, and Epstein Barr virus often cause acute liver injury, ${ }^{15,16}$ whereas hepatitis $\mathrm{C}$ virus (HCV) and hepatitis B virus (HBV) lead to chronic liver injury. ${ }^{17,18}$ The acute liver injury involves much

${ }^{1}$ Department of Surgery, University of Illinois College of Medicine at Peoria, Peoria, IL 61605, USA

${ }^{*}$ Corresponding author: K Wang, Department of Surgery, University of Illinois College of Medicine at Peoria, One Illini Drive, Peoria, IL 61605, USA. Tel: +1 309680 8617; Fax: +1 309680 8617; E-mail: kewang@ uic.edu

Keywords: hepatic apoptosis; liver injury; ROS; ER stress; lysosomal permeabilization; mitochondrial dysfunction

Abbreviations: ROS, reactive oxygen species; CYP2E1, cytochrome P450 2E1; Drat, death resistor ADH domain containing target; ADH, alcohol dehydrogenase; ALDH, acetaldehyde dehydrogenase; ADHr, ADH-related; $\mathrm{NAD}^{+}$, nicotinamide adenine dinucleotide; ER, endoplasmic reticulum; ATP, adenosine triphosphate; MTP, mitochondrial permeability transition; NASH, non-alcoholic steatohepatitis; UDCA, ursodeoxycholic acid; HNF6, hepatocyte nuclear factor 6; iNOS, inducible NO synthase; IFN $\gamma$, interferon-gamma; IL-6, interleukin 6; NF- $\kappa$ B, nuclear factor kappa-light-chain-enhancer of activated B cells; TNF $\alpha$, tumor necrosis factor alpha; TNFR, tumor necrosis factor receptor; TRAIL, TNF-related apoptosis-inducing ligand; FADD, Fas-associated protein with death domain; RNS, reactive nitrogen species; PUMA, p53-upregulated mediator of apoptosis; UTR, untranslated region; PDC-E2, E2 component of the pyruvate dehydrogenase complex; IAPs, inhibitors of apoptosis proteins; $\mathrm{CI} / \mathrm{WR}$, cold ischemia/warm reperfusion

Received 13.3.13; revised 07.11.13; accepted 07.11.13; Edited by A Stephanou 
necrosis, but the chronic infection of HCV and HBV exhibits abundant apoptosis. Only human and chimpanzee hepatocytes are naturally able to support HCV entry, likely due to differences in tropism determinants. A successful HCV infection requires many cellular factors, for example, OCLN, CLDN1, GAGs, SR-BI, LDL-R, and CD81. ${ }^{19-23}$ Speciesspecific entry factors may include ample levels of OCLN and CD81 with large extracellular loop. ${ }^{24}$ CLDN1 and SR-BI only expressed in hepatocytes are cell entry tropism determinants. ${ }^{25,26} \mathrm{HCV}$ replication and production in infected hepatocytes can induce apoptosis and a release of inflammatory cytokines/chemokines, such as tumor necrosis factor alpha (TNF $\alpha$ ), TGF $\beta$, interferon-gamma (IFN $\gamma$ ), interleukin 10 (IL-10), IL-12, IL-22, CCL3, CCL4, CXCR3 ligand, IP-10, CCR5 ligands, and RANTES. ${ }^{27-31}$ These inflammatory cytokines/chemokines can stimulate hepatocyte apoptosis through different pathways. For instance, TNF $\alpha$ is a classical cytokine and its signaling pathway had been well investigated (Figure 1). Special structures of HCV genome determine particular entry pattern of infectious $\mathrm{HCV}^{32} \mathrm{HCV}$ genome encodes structural proteins core, E1, E2, and P7 as well as non-structural proteins NS2, NS3, NS4A, NS4B, NS5A, and NS5B. HCV core protein can sensitize TNF-related apoptosis-inducing ligand (TRAIL)-induced apoptosis(Figure 2). ${ }^{33,34}$ The HCV core protein also binds to tumor necrosis factor receptor 1 (TNFR1) to trigger $\mathrm{TNF} \alpha$-induced apoptosis via increasing expression of Fas-associated protein with death domain (FADD) and to initiate Fas-induced apoptosis through the formation of the death-inducing signaling complex. ${ }^{35,36}$ NS3 protein can additionally sensitize to Fasinduced apoptosis. ${ }^{37}$ Expression of E1 and E2 in murine hepatocytes can increase the apoptosis of activated T cells, providing a possible mechanism for immune escape in chronic infection. ${ }^{38}$ Moreover, Core, NS3, NS4B, and NS5A are the major immunogenic proteins in chronic $\mathrm{HCV}$ infection. An enhanced Fas expression in HCV-infected hepatocytes leads to T cell-mediated apoptosis. Fas-mediated apoptosis shows a much high level as alcohol consumption in hepatitis $\mathrm{C}$ patients. ${ }^{39}$ There is promising Fas-mediated apoptosis in HCV infection that correlates with the level of serum alanine aminotransferase and histologic grade. The cytokeratin-18 neoantigen (M30), reflecting ongoing hepatocyte apoptosis, is elevated in patients with chronic hepatitis $\mathrm{C} .{ }^{40}$ The $\mathrm{M} 30$ may be a surrogate to replace the repeated liver biopsy. HBV nucleocapsid encloses viral DNA and DNA polymerase. ${ }^{41}$ The outer envelope contains embedded proteins that are involved in viral binding of, and entry into susceptible cells. Chronic HBV infection is characterized by certain levels of hepatocyte apoptosis. Hepatic TNF $\alpha$, TNFR1, and Fas expression (also serum Fas) is enhanced in chronic HBV infection and correlated with degree of liver injury. ${ }^{42,43}$ Fas-expressing lymphocytes penetrate areas of apoptotic hepatocytes in patients with fulminant hepatic failure due to HBV. TRAIL expression in NK cells increases in temporal correlation with levels of serum alanine aminotransferase. In clinical, TRAIL receptor 2 is upregulated in livers of patients with chronic HBV. ${ }^{44} \mathrm{Bax}$ expression in hepatocytes is positively correlated with the number of apoptotic nuclei. HBx protein can upregulate TRAIL-receptor expression and sensitizes hepatocytes to



Figure 1 Model of HCV apoptotic signaling pathways. HCV induces infected hepatocytes to apoptosis. Death receptor-mediated extrinsic pathway is enforced by mitochondrial amplification loop. Oxidative and ER stress with apoptosis are also shown, which reflect a potential interaction between the host cell response and apoptosis. Stress pathways are converged at the nucleus and low levels of NF- $\kappa$ B and $\mathrm{BCL}-\mathrm{xL}$ sensitize hepatocytes to apoptosis. Lines with arrows denote an activating reaction; red lines ending in perpendicular lines denote inhibition of the reaction

- Structural proteins: core, E1, E2, and p7.

- Nonstructural proteins:NS2, NS3, NS4A, NS4B, NS5A, and NS5B.

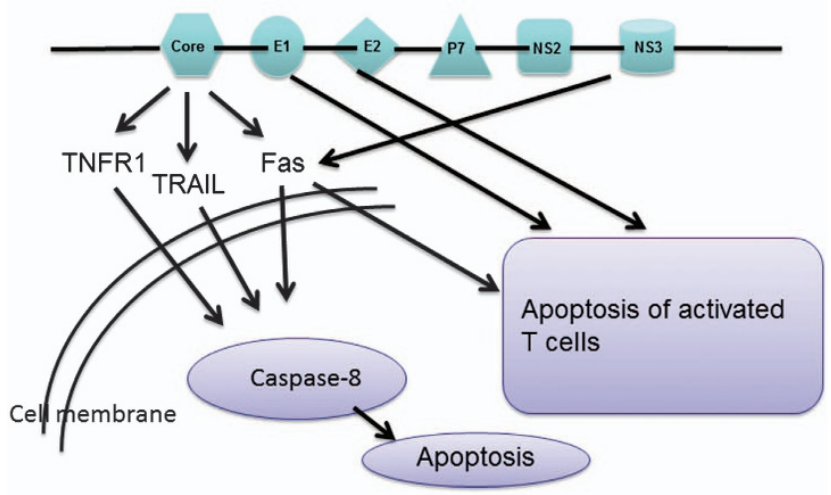

Figure 2 Role of HCV viral proteins in the induction of apoptosis. The positivestranded genome RNA of HCV encodes structural proteins (core, E1, E2, and p7) and non-structural proteins (NS2, NS3, NS4A, NS4B, NS5A, and NS5B). Special structures of HCV genome determine not only particular entry pattern of infectious $\mathrm{HCV}$, but death mode of infected hepatocytes and immune escape mechanism as well

TRAIL toxicity, leading to TRAIL-mediated apoptosis. ${ }^{45,46}$ Liver injury is triggered by host immune response to hepatocytes expressing viral proteins. HBV infection regulates the apoptotic machinery to establish persistent infection and evade the immune system. Like HCV, HBV can chronically infect the host as well, eliciting chronic liver injury to fibrosis/cirrhosis and the sequelae of advanced liver disease. Both HBV and HCV mediate adaptive and innate immune responses in liver, which can induce target cell apoptosis, a feature common in these viral liver diseases. The infection of HCV and HBV also is a principal risk factor of hepatocellular carcinoma. ${ }^{47}$ A complete understanding toward mechanisms of hepatotropic virus-mediated apoptosis will help to develop therapeutic drugs. 
Alcohol. Long-term use of alcohol in excessive quantities leads to the development of alcoholic liver disease (ALD). ${ }^{48}$ Acute and chronic alcohol consumption induces much production of reactive oxygen species (ROS), lowers cellular antioxidant levels, and enhances oxidative stress in the liver tissue. $^{49}$ During the body's metabolic reactions, highly reactive ROS is naturally generated in small amounts. However following the exposure of alcohol, massive ROS actively reacts with and damages complex cellular molecules such as lipids, proteins, or nucleotides. Alcohol-induced oxidative stress has a major role in the mechanism by which alcohol causes liver injury. Many signaling molecules take part in alcohol-induced oxidative stress. Cytochrome P450 2E1 (CYP2E1), as an effective generator of ROS, can produce superoxide anion radical, hydrogen peroxide, and powerful oxidants such as the hydroxyl radical in the presence of iron catalysts (Figure 3). ${ }^{50,51}$ Although levels of CYP2E1 are elevated under a variety of physiological and pathophysiological conditions, alcohol is a strong inducer to alter a state of oxidative stress through the induction of CYP2E1. ${ }^{52}$ Alcohol abuse stimulates an overproduction of ROS and leads to hepatic apoptosis via mechanism of oxidative stress. Except for oxidative stress, the impact of alcohol on hepatocytes also includes mitochondrial dysfunction, decreased methylation capacity, endoplasmic reticulum stress, impaired vesicular trafficking, and altered proteasome function. ${ }^{53}$ By employing Drosophila as a model system, a novel apoptogenic effector Drat (death resistor alcohol dehydrogenase (ADH) domain containing target) was identified, which could regulate cell death incited by alcohol challenge as well. Drat function was required for alcoholinduced apoptotic cell death. ${ }^{54}$ Although ADH and acetaldehyde dehydrogenase (ALDH) influence responses to alcohol, interestingly alcohol-induced cell killing in Drosophila model was unaffected by depletion of $A D H$ and $A D H$-related $(A D H r)$ alone or in combination. Surprisingly, $A L D H$ depletion failed to enhance the apoptogenic effects of alcohol. These results reveal that alcohol itself, rather than its metabolites, triggers apoptotic process in Drosophila system. The alcoholic liver injury involves both the parenchymal and non-parenchymal cells in the liver. The occurrence of apoptotic bodies generated from hepatocytes activates Kupffer cells (KCs) (Figure 4). ${ }^{55}$ Alcohol treatment results in an enhanced responsiveness of KCs and produces inflammatory cytokines as indicated in alcohol-fed animals. Alcohol exposure also alters the expression of endotoxin receptors and intracellular signaling molecules, which causes both tolerance and sensitization of KCs to endotoxin. Tolerance of KCs may contribute to the impairment of innate immune system in alcoholism, while sensitization to endotoxin enhances progression of alcoholic liver injury. Alcohol awakens KCs to be sensitized by lipopolysaccharides via toll-like receptor 4 (TLR4). ${ }^{56}$ This sensitization promotes the production of TNF $\alpha$ and ROS. These inflammatory mediators contribute to hepatocyte dysfunction, apoptosis and necrosis of hepatocytes, and the generation of extracellular matrix proteins leading to characteristic fibrosis. Inflammatory and innate immune responses in KCs due to elevated lipopolysaccharide, increased oxidative stress, and profibrogenic factors such as acetaldehyde or lipid peroxidation products



Figure 3 Molecular mechanism of alcohol-mediated hepatocyte apoptosis. Alcohol is metabolized in the liver and can be converted into acetaldehyde. As a toxic substance, the acetaldehyde induces hepatocyte apoptosis. Alcohol breakdown by cytochrome P450 2E1 (CYP2E1) also generates highly reactive molecules known as reactive oxygen species (ROS), particularly after chronic alcohol consumption. ROS can be eliminated by antioxidants such as glutathione (GSH). When cell's antioxidants are depleted and ROS accumulation reaches a critical threshold, mitochondrial damage occurs. This process leads to the release of cytochrome $c$ from the mitochondria, which then activates caspases apoptotic pathway

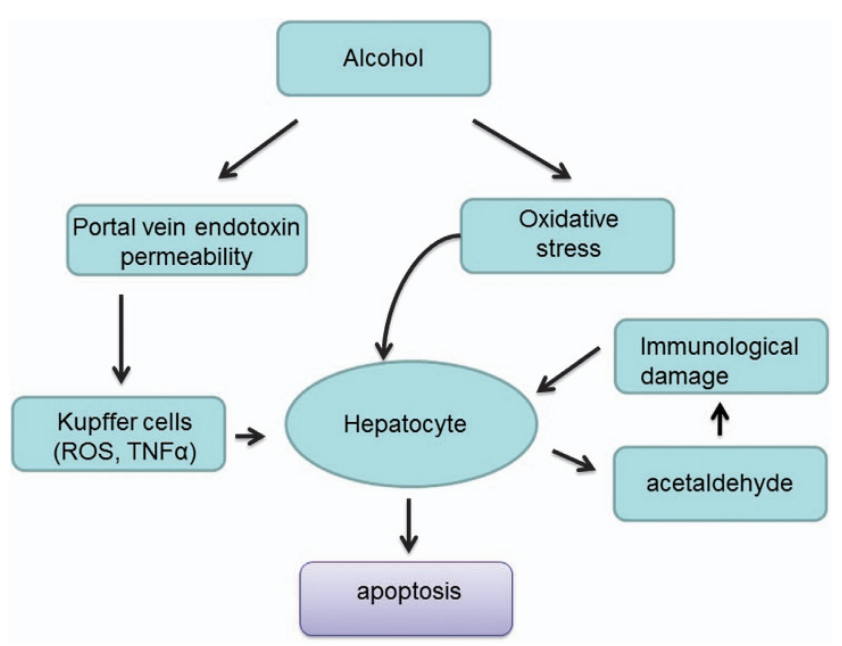

Figure 4 Signaling mechanism of alcoholic liver injury. Oxidative stress is an important mechanism in alcoholic liver disease. Moreover, alcohol increases levels of bacterial endotoxin in the liver, which further activates liver Kupffer cells to produce inflammatory cytokines (e.g., TNF $\alpha$ ) and/or chemokines (e.g., IL-8). The acetaldehyde interacts with proteins in the liver, forming compounds called adducts that can additionally activate certain immune cells to produce various cytokines, including interleukins, IFN $\gamma$, and TNF $\alpha$. All of these diverse pathways contribute to the induction of apoptosis and organ damage

contribute to activation of hepatic stellate cells (HSCs). ${ }^{57}$ Alcohol exposure can alter the structural integrity of hepatic sinusoidal endothelial cells and activates HSCs. The activated HSCs transform into the collagen-producing cells and the wound-healing response to recurrent liver injury is triggered, which results in excessive accumulation of extracellular matrix proteins, mainly collagen type I. When fiber 
synthesis is very active and the decomposition is suppressed, fibrosis will progress. Oppositely, fibrosis can be reversed if the driver, inflammation, is controlled. ${ }^{58}$ Hepatocyte apoptosis, inflammation, and fibrosis are apparent features of liver disease in general and of alcoholic liver injury in particular. A comprehensive understanding on ALD mechanisms remains incomplete. The development of therapeutic interventions for ALD is still under way.

Toxic bile acids. The accumulation of bile acids or cholestasis can cause liver dysfunction, cirrhosis, and liver failure. ${ }^{59}$ The causes of cholestasis include genetic defects, mechanical aberrations, toxins, and dysregulation in the immune system. ${ }^{60}$ Cholestatic animal models such as partial or total bile duct ligation (BDL) can approximately mimic clinical obstructive cholangiopathies, for example, biliary strictures and biliary atresia. Hepatic apoptosis is a routine manifestation of hepatobiliary injury in BDL models. ${ }^{61}$ Membrane death receptor-mediated caspase activation is an important pathway during cholestatic liver injury. ${ }^{62}$ The mitochondrial pathway is often required to amplify the relatively weak death receptor-induced apoptotic signal in liver cells. ${ }^{63}$ Typical apoptosis of cholestatic liver injury is induced through Fas-dependent, ligand-independent aggregation of Fas receptor complex, recruitment of the apoptotic TRAIL receptors, and TNF $\alpha$ cascade (Figure 5). ${ }^{64-66}$ Bile acids are normally secreted rapidly from hepatocytes by transporters located in the canalicular membrane. In cholestasis, secretion is impaired, resulting in elevated concentrations of toxic bile acids (TBAs) within hepatocytes. As concentrations of TBA reach a certain threshold, intracellular bile acids modulate vesicular targeting and oligomerization of the Fas receptor, which translocates internal Fas bearing vesicles to the plasma membrane where they self-aggregate in the absence of ligand. Activated Fas receptor complexes on the plasma membrane then cause caspase- 8 activation

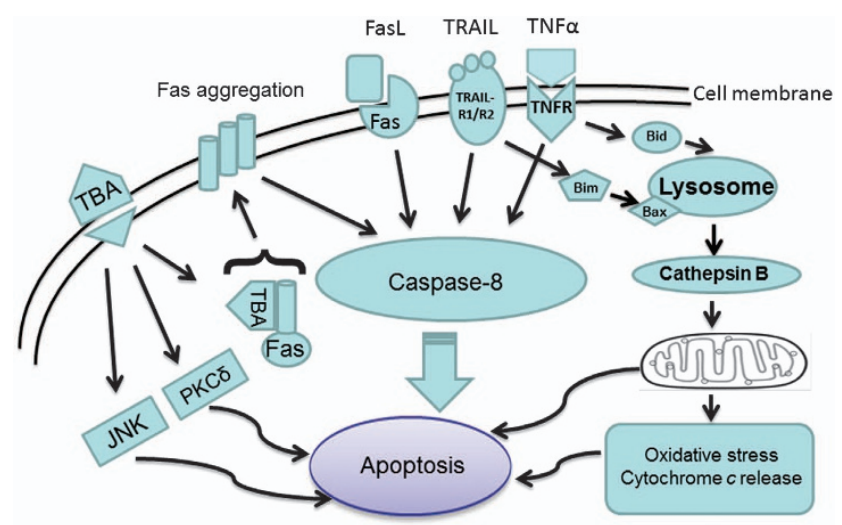

Figure 5 Toxic bile acids (TBAs)-induced hepatocyte apoptosis. In cholestasis, bile secretion is impaired, resulting in elevated concentrations of TBAs within hepatocytes. TBAs can activate the ER stress pathway as well as generation of ROS. TBAs also sensitize hepatocytes to death receptors (Fas, TRAIL, and TNF $\alpha$ )induced apoptosis. Particularly, TBAs trigger translocation of intracellular Fas bearing vesicles to the plasma membrane where they self-aggregate, activate Fas receptor complexes, and cause caspase apoptotic cascade. In addition, some bile acids also activate PKC- $\delta$ and/or JNK1/2 MAP kinase, both of which stimulate proapoptotic pathways and an apoptotic cascade. ${ }^{67}$ TBA induce hepatocyte apoptosis by both Fas-dependent and -independent mechanisms via activation of caspases. Another mechanism by which apoptosis occurs beyond bile acid-mediated injury includes overexpression of $\mathrm{TNF} \alpha$ and its interlinking with receptors TNFR1 and TNFR2 to activate the caspase pathway in BDL mice. ${ }^{68}$ Induction of TRAIL-R2/DR5 expression and apoptosis by toxic GCDC in vitro provides new insights into the mechanisms of hepatocyte apoptosis. ${ }^{69}$ In support of this mechanism, human cholangiocytes constitutively express TRAIL and apoptosis is significantly elevated in cholangiocytes of human primary sclerosing cholangitis (PSC) and primary biliary cirrhosis (PBC) patients, implicating TRAIL-mediated apoptosis in the progression of chronic cholestatic diseases, particularly PSC. ${ }^{70}$ Parenchymal liver injury by BDL and clinical obstructive cholangiopathies all result in hepatic apoptosis and dysfunction. Moreover, hepatic apoptosis can stimulate the profibrotic KCs that amplify the proinflammatory cascade and initiate the fibrogenic response. The early course of BDL is characterized by biliary epithelial proliferation within $24 \mathrm{~h}$ of obstruction. This is followed by inflammatory cell infiltrates consisting of mostly polymorphonuclear cells. ${ }^{71}$ This is associated with the upregulation of inflammatory cytokines, such as the proapoptotic TNF $\alpha$ and mitogenic IL-6. By the second week of biliary obstruction, extracellular matrix proteins such as collagen, laminin, and elastin are deposited in the periductal space and by the third week of obstruction, early evidence of biliary cirrhosis shown as the presence of liver parenchymal nodules and dense portal fibrotic septa is found. The transforming growth factors (TGF-b1/TGF-b2) have been implicated as the dominant soluble mediators for parenchymal fibrosis. ${ }^{72}$ The relationship between apoptosis and pathologic hepatic fibrosis has been appreciated in recent years. ${ }^{73}$ In bile acid pool, glycochenodeoxycholic acid is cytotoxic and can induce hepatocyte apoptosis as demonstrated by in vitro or in vivo models, whereas ursodeoxycholic acid (UDCA) is cytoprotective. ${ }^{67,74}$ UDCA can stabilize cell membrane of hepatocytes, increases defense against oxidative stress, and inhibits apoptosis. UDCA or its derivative has been utilized in clinical patients to improve liver function in some liver disease. ${ }^{75}$ Moreover, the upregulated hepatocyte nuclear factor 6 (HNF6) is liver protective through a mediation of bile transport. ${ }^{76}$ A variety of pathways contribute to liver damage and the reparative response, so novel therapies may be developed when targets that mediate these processes are identified.

Fat. Accumulation of fat (or fatty infiltration) in the liver can induce liver injury. Pathological changes of non-alcoholic fatty liver disease (NAFLD) include simple steatosis as well as complex lesions of steatohepatitis with varying degrees of steatosis, inflammation, ballooning degeneration, and fibrosis. Progressive steatohepatitis leads to cirrhosis. ${ }^{77}$ Mechanisms of NAFLD are closely linked to abnormalities in insulin response, lipid metabolism and disposition, and chronic inflammatory/oxidative stress response. ${ }^{78}$ Obesity, defined as body mass index greater than $30 \mathrm{~kg} / \mathrm{m}^{2}$, is a principal risk factor associated with NAFLD. ${ }^{79}$ In obesity, fat laden myocytes and adipocytes become resistant to insulin 
signaling. Therefore, it leads to hyperglycemia, hyperlipidemia, and fat deposition in non-adipose tissues such as muscle and liver. Increased intrahepatic fat impairs insulin signaling in the liver and accelerates liver gluconeogenesis. c-Jun amino-terminal kinases (JNKs) can interfere with insulin action in cultured cells and are activated by inflammatory cytokines, free fatty acids (FFAs), and molecules that have been implicated in the development of type II diabetes. ${ }^{80,81} \mathrm{JNK}$ becomes a potential target for therapeutics. Sensitization to death ligands may also occur independently of JNK activation in vivo, which is known to mediate insulin resistance and liver injury in models of dietary obesity. Inflammatory cytokines such as IL- 6 and TNF $\alpha$ are produced by monocyte/macrophages and adipocytes. ${ }^{82}$ Along with FFAs, they modulate insulin sensitivity by altering the phosphorylation state of insulin receptor substrates. The lipid oxidation response mediated by lipotoxic fat, and mitochondrial, peroxisomal or microsomal CYP2E1 and CYP4A enzymes are increased as well. ${ }^{83}$ Excess ROS and lipid peroxidation products are neutralized by free radical scavenger response, or with upregulation of mitochondrial uncoupling protein 2 (UCP-2). UCP-2 protective response to reduce $R O S$ production by limiting mitochondrial adenosine triphosphate (ATP) synthesis, however, depletes ATP production under stress. ${ }^{84}$ In the face of diminished antioxidant response, cells are susceptible to mitochondrial damage and cellular apoptotic injury. FFAs induce lipoapoptosis in hepatocytes, which is an obvious feature in nonalcoholic steatohepatitis (NASH). ${ }^{85}$ Toxic FFAs can activate the lysosomal pathway of cell death, sensitizing cells to cytokine toxicity. Elevated expression of Fas, TNF receptor, and TRAIL receptor 2 is found in liver biopsy samples. ${ }^{86,87}$ Furthermore, FFAs can stimulate the intrinsic apoptosis pathway via JNK, which is mediated by intracellular Bim levels and Bax activation, leading to mitochondrial permeabilization, cytochrome $c$ release, and caspase activation. Thus, JNK-dependent lipoapoptosis is significantly modulated by proapoptotic protein Bim/Bax activation. ${ }^{88}$ In addition, levels of adiponectin are reduced, which increases vulnerability to lipotoxicity and promotes progression from simple steatosis to NASH and even advanced hepatic fibrosis. Blood caspase target M30 is elevated in patients with NASH and serum levels are correlated with hepatic levels. Saturated FFAs induce Bim expression and cell stress, lead to sustained JNK activation, and sensitize hepatocytes to death receptor (Fas and TRAIL)-mediated apoptosis (Figure 6). ${ }^{87}$ Hepatocyte apoptosis closely correlates with hepatic inflammation and fibrosis. Inflammatory cytokines from visceral adipose tissue or enteric sources further sensitize the liver to oxidative stress and cellular injury. In particular, TNF $\alpha$ can exacerbate NAFLD by inducing mitochondrial ROS, by activating stress-related kinases that inhibit insulin signaling and promote gluconeogenesis, by suppressing adiponectin anti-lipogenic effect to compound steatosis, and by attenuating the anti-inflammatory effects of adiponectin and PPAR $-\gamma{ }^{89,90}$ Therefore, secondary inflammation and fibrosis of NAFLD ensue. Hepatic lipid turnover is also regulated by transcription factors ChREBP, SREBP-1c, Foxa2, C/EBP $\alpha$, and PPAR. ${ }^{90-93}$ The dysregulation of microRNAs (miRNAs)

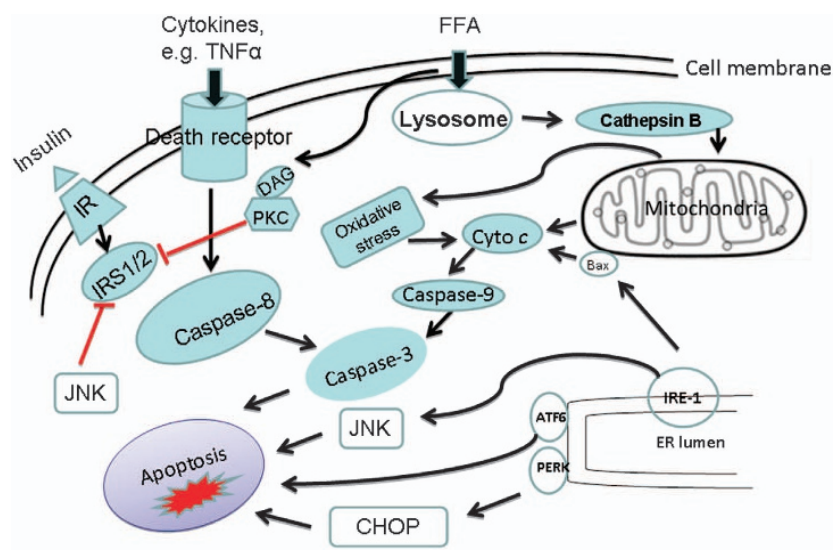

Figure 6 Possible pathways of fat-induced hepatic apoptosis. The distinct mediators of fatty liver disease may include circulating cytokines, adipokines, and free fatty acids (FFAs). Peripheral insulin resistance enhances the delivery of FFAs to the liver, resulting in an imbalance of FFA metabolism and synthesis, thus promoting hepatic steatosis. Steatotic livers increase inflammatory cytokines, ROS, and ER stress, which trigger apoptotic cascade. Insulin sensitivity is further impaired by JNK-mediated phosphorylation of IRS1 and 2. Moreover, adipocytokines such as leptin and adiponectin are regulated by levels of circulating cytokine such as TNF $\alpha$

contributes to metabolic disorders. ${ }^{94,95} \mathrm{miR}-33 \mathrm{a}, \mathrm{miR}-33 \mathrm{~b}$, miR-34a, and miR-122 may be associated with the pathogenesis of NAFLD and its progression to NASH. ${ }^{94,96}$ Two miRNAs, miR-34a and miR-296, were involved in the regulation of hepatocyte apoptosis. Particularly, the miR-34a/ Sirtuin 1(SIRT1)/p53 proapoptotic pathway in human NAFLD could be suppressed by UDCA. ${ }^{97}$ miR-296-5p directly binds to p53-upregulated mediator of apoptosis (PUMA) $3^{\prime}$-untranslated region (UTR) and negatively regulates its expression. An altered miR-296-5p could regulate PUMA expression and hepatocyte lipoapoptosis. In NASH patients with increased circulating FFAs, hepatic miR-296 expression was decreased, resulting in an amplification of PUMA with associated lipotoxicity. ${ }^{98}$ The future study will pay attention to the relevance of insulin resistance, hyperlipidemia, cytokines, oxidative stress, and adaptive response in obesity pathologies along with novel areas of obesity research such as the role of hepatic transcription factors and target genes in regulating lipid metabolism and fat disposal.

Drugs. Liver is a crucial organ of metabolism and elimination of foreign substances. Liver therefore is a preferred target for drug toxicity. ${ }^{99}$ Drug-induced liver injury (DILI) can mimic all forms of acute or chronic liver disease. The pathogenesis of DILI includes cell stress, mitochondrial impairment, and specific immune reactions. ${ }^{100,101}$ Current concepts emphasize the central role of mitochondria, of events leading to apoptotic and/or necrotic cell death, and of factors that balance injurious and protective responses. Liver as the central place of detoxification is constantly exposed to cell stress. Cell stress breaks the balance of inflammatory cytokines that promote (e.g., IL-12) or prevent (e.g., IL-4, IL-10, IL-13, MCP-1) injury. ${ }^{102-104}$ Consequently, liver cells become more susceptible to lethal effects of $\operatorname{TNF} \alpha$, Fas ligand (FasL), and IFN $\gamma^{105}{ }^{105} \mathrm{TNF} \alpha$ and FasL bind to intracellular death receptors. TNF and Fas receptor-associated 
death domain proteins will subsequently activate initiator caspase-8. The caspase-8 can start apoptosis through a direct activation of effector caspases-3, 6, and 7. In mitochondria, drugs or their reactive metabolites act on the mitochondrial respiratory chain to cause a series of harmful response, such as ATP depletion, production of ROS, inhibition of $\beta$-oxidation, mitochondrial DNA damage, and an increase in the permeability of the mitochondrial membranes (Figure 7). ${ }^{100,106}$ As an accumulation of cytosolic ROS and JNK activation more than critical threshold, the mitochondrial damages cause mitochondrial membrane permeabilization, release of cytochrome $c$, and activation of pro-caspase-9. The active pro-caspase- 9 subsequently activates executioner caspase- 3 that cleaves specific target proteins and results in apoptotic death. If initial injury is so severe that MPT quickly occurs in all mitochondria and rapid ATP depletion, then necrosis will develop. There is no clearcut to discriminate apoptosis and necrosis. The same hepatotoxin may cause the concomitant occurrence of both death modes, depending on the circumstances including dose and preexisting vulnerability of hepatocytes. The mode of cell death by toxic stimuli is often concentration dependent, with more likely apoptosis at low concentrations and necrosis at high concentrations. For all mechanisms, mitochondria have a central role in chain events leading to apoptotic and/or necrotic cell death. The mitochondrial pathway can also amplify the relatively weak death receptor-induced apoptotic signal in liver. Acetaminophen (N-acetyl-para-aminophenol (APAP), paracetamol)-induced hepatotoxicity remains one of major clinical problems in the field of DILI. ${ }^{107}$ APAP could markedly amplify the TRAIL signaling pathway to induce apoptosis in hepatocyte-like cell lines, primary hepatocytes, and liver sinusoidal endothelial

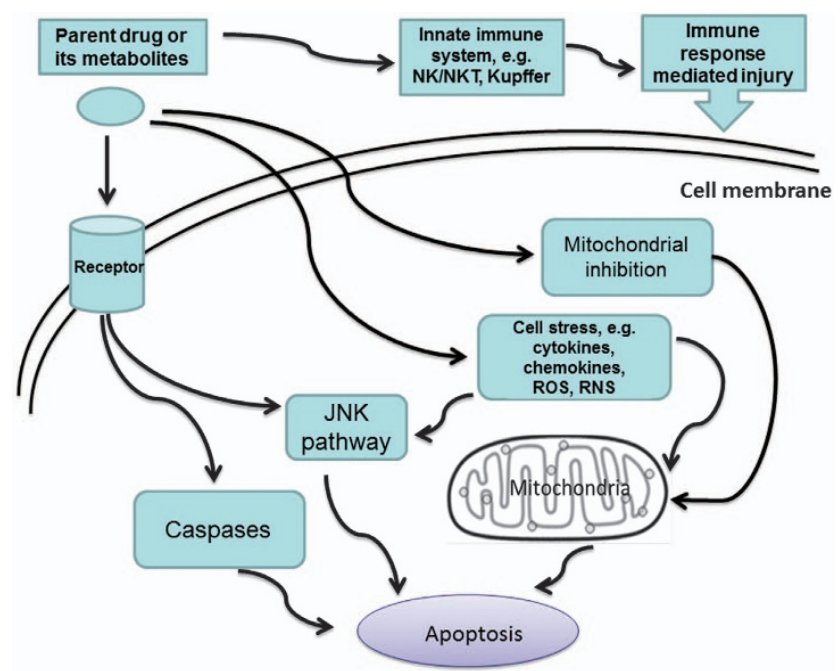

Figure 7 Potential mechanisms for drug-induced hepatic apoptosis. Pathogenesis of drug-induced liver injury (DILI) includes cell stress, mitochondrial impairment, and specific immune reactions. Parent drugs or their reactive metabolites can cause cell stress to produce cytokines, chemokines, ROS, and reactive nitrogen species (RNS). Current concepts emphasize the central role of mitochondria, which leads to apoptotic and/or necrotic cell death. Hepatocytes, Kupffer cells, and even endothelial cells all participate in DILI. Inflammatory mediators of innate immune system determine the outcome of DILI cells. ${ }^{108,109}$ Especially, TRAIL-induced cell death could be efficiently attenuated by pan-caspase inhibitor Z-VADfmk. ${ }^{109}$ TRAIL- or Bim-deficient mice were substantially protected from APAP-induced liver damage. ${ }^{108}$ Toll-like receptor 3 (TLR3, CD283) also contributed to APAP-induced liver damage. ${ }^{107}$ The activation of TLR3 was required for APAP-induced liver failure as proven in TLR3-deficient mice. The TLR3 activation could stimulate the TNF $\alpha$ production and the expression of phosphorylated JNK in APAP-injured livers. Future perspectives will focus on the understanding of pathogenetic mechanisms of DILI. There are no pathognomonic indicators for DILI, even if liver biopsy is not diagnostic. ${ }^{110}$ New marker for apoptosis such as the monoclonal $\mathrm{M} 30$ antibody, recognizing a caspase-generated cytokeratin-18 neoantigen, may be useful in the early diagnosis of DILI. ${ }^{111}$ JNK acts on acetaminophen metabolism to induce hepatotoxicity. JNK inhibitor is thus used in clinical patients with acetaminophen-induced liver injury. ${ }^{112}$ Caspase inhibitors block apotpotic cascade to reduce liver injury. Caspase inhibitors may be applied in the treatment of DILI. Anti-apoptotic role of inhibitors of apoptosis proteins (IAPs) or Bcl-2 proteins makes them potentially to be utilized in clinical practice of DILI. ${ }^{113}$ Although UDCA has a panantiapoptotic role through the modulation of MPT, its use in the treatment of DILI patients is still to be determined. Actually, inhibition of apoptosis is becoming a new strategy to develop therapeutics of DILI.

Immunologic factors. Immune-mediated mechanism can be either an independent factor or an interactive factor to trigger the pathogenesis of liver injury. For instance, HCV persistent infection or exposure of self-antigen uncovered by the viral infection can stimulate immune reaction. The mechanisms that lead to the establishment of immune evasion and persistent infection are complex and beyond the scope of this review. The immune response has also involved hepatobiliary diseases such as PBC, PSC, and autoimmune hepatitis. ${ }^{114}$ These diseases can also cause an accumulation of TBAs that exacerbate hepatic apoptosis. PBC is characterized by inflammatory destruction of small and medium size intrahepatic bile ducts, eventually leading to liver failure. PBC can be initiated by mechanisms that lead to loss of tolerance toward mitochondrial antigens. A proposed theory contains that (i) pre-existing genetic condition perpetuates the destruction of the biliary epithelium by the immune system; (ii) the modifications of mitochondrial autoantigens by infectious agents and/or xenobiotics; (iii) the unique apoptotic features of biliary epithelial cells (BECs) (Figure 8). ${ }^{115}$ Autoimmune characteristics of PBC ensue from a multi-lineage loss of tolerance to PDC-E2 (E2 component of the pyruvate dehydrogenase complex). BECs handle PDC-E2 and attract immune attack by virtue of the unique biochemical mechanisms. ${ }^{116}$ The apoptosis of BECs in PBC is secondary to the invasion of inflammatory cells. BECs have ability to phagocyte apoptotic BECs and present mitochondrial derived self-peptides. ${ }^{117}$ The apoptosis of BECs may be a potential source of 'neo-antigens' that are responsible for activating autoreactive lymphocytes, as many autoantigens are selectively modified during apoptosis and may facilitate molecular mimicry or autoimmunity. PSC is 




Figure 8 Pathogenesis of immune-mediated apoptotic liver injury. The liver has big population of Kupffer cells, dendritic cells, NK cells, and NKT cells. An innate immune response is initiated when antigens are presented by antigen-presenting cells (APCs) which then activate, directly and/or indirectly, NKT cells and other innate immune cells. The apoptosis of biliary epithelial cells (BECs) is a potential source of 'neo-antigens' that may be responsible for facilitating molecular mimicry or autoimmunity. NKT cells upregulate FasL on their surface which binds to the Fas receptor expressed on target hepatocytes, leading to apoptosis. Activation of NKT cells can also indirectly induce hepatocyte apoptosis through the release of cytokines, including IFN $\gamma$ and TNF $\alpha$. Th2 responses are also induced due to the presence of IL-4, which then promote maturation of B cells into plasma cells for the production of autoantibodies. Furthermore, IL-17 family has been linked to many immune/autoimmune-related diseases

another chronic liver disorder shown by inflammatory destruction of small intrahepatic bile ducts as well as extrahepatic bile ducts. ${ }^{118}$ PSC is strongly related to inflammatory bowel disease, colorectal cancer, osteoporosis, and cholangiocarcinoma. ${ }^{119-121}$ The role of specific gene deficiencies in the susceptibility to immune-mediated cholangiopathies is highlighted. Effector mechanisms of adaptive immunity lead to bile duct epithelial apoptosis. PSC as an immune-mediated liver disease is associated with apoptotic death as reflected by programmed cell death ligands and circulating apoptotic markers. In general, apoptosis can be initiated via an extrinsic pathway that is triggered by engagement of death receptors on the cell surface, or via an intrinsic pathway that is induced by mitochondrial injury and is influenced by members of the Bcl-2 family. In both pathways, effector caspases are finally activated, which cleave and degrade cell structures, resulting in the release of apoptotic products into the circulation. New diagnostic tests can detect these apoptotic markers that include nucleosomes, caspases, cytokeratin fragments, macrophage migration inhibitory factor, soluble intracellular adhesion molecule, natural killer cells group 2D, and programmed death ligands such as Fas and Fas ligands. ${ }^{122}$ Concanavalin A (Con A)-induced liver injury is an experimental model of immune-mediated liver diseases. ${ }^{123}$ Con $A$ has high affinity toward the hepatic sinus. After Con A injection, high levels of the cytokines IL-2, TNF $\alpha$, IFN $\gamma$, IL-6, GM-CSF, and IL-1 are found, which result in the activation of CD4 cells. ${ }^{124}$ Con A-induced cytokines such as TNF $\alpha$ and IFN $\gamma$ have direct implications for the induction of a broad hepatic apoptosis, which mimics clinical fulminant hepatic failure. Non-peptide caspase inhibitor not only protected hepatocytes from the fatal apoptogenic effect of Con A, but also suppressed the elevation of AST and ALT and IL-1 beta concentration. ${ }^{125}$
Inducible NO synthase (iNOS) and nuclear factor kappalight-chain-enhancer of activated $B$ cells $(N F-\kappa B)$ also involve Con A-induced autoimmune liver injury. ${ }^{126,127}$ Immunopathogenesis and apoptotic mechanisms are crucial to develop therapeutic approaches for immune-mediated liver diseases.

\section{Summary and Future Study}

Mechanisms of hepatic apoptosis are scrutinized here. It is worth noting that (i) apoptosis cannot be thought of as an exclusive mechanism. Apoptosis is actually intermingled with other cell death modes such as necroptosis and necrosis. For instance, TRAIL-induced apoptosis could be switched into regulated necrosis (or necroptosis) in human HT29 and HepG2 cells under acidic extracellular condition. The role of TRAIL as inducer of necroptosis had also been shown in a mouse model of Con A-induced hepatitis, where death of hepatocytes was dependent on TRAIL and natural killer T cells. ${ }^{128}$ Inhibition of apoptosis is not sufficient to prevent liver injury in some models. The role of necrosis may be more than that of apoptosis in cholestatic livers; ${ }^{129}$ (ii) multiple signaling pathways should be considered even in single causative factor (e.g., virus). Viral infection can activate an apoptotic network, including death receptor-mediated cascade, ER stress, lysosomal permeabilization, ROS generation, and mitochondrial dysfunction. All of these mechanisms are intermixed each other. Probably, one mechanism dominates in a particular stage. For example, lysosomal involvement in cell death is an early event before mitochondrial permeabilization or caspase activation. Mitochondrial dysfunction is a prerequisite for hepatocyte apoptosis; (iii) pathophysiologic role of apoptosis is sophisticated by its contradictory facts. Current data indicate that blocking hepatic apoptosis (e.g., deletion of caspase-8) may also trigger an increased liver necrosis or necroptosis. ${ }^{130,131}$ A lack of apoptosis or enhanced liver apoptosis may both result in hepatocellular cancer depending on the tissue environment. ${ }^{132,133}$

There are expectable perspectives for therapeutics of liver diseases. Inhibition of hepatic apoptosis can reverse or delay the progression of liver diseases, which had been demonstrated by pre-clinical models and clinical trials. The hydrophilic bile salt UDCA inhibited TBA-induced apoptosis. UDCA and its derivative have been using for a long time to treat cholestatic liver diseases, for example, PBC and PSC. ${ }^{74}$ Caspase inhibitors may be a promising treatment option in patients with liver diseases. Caspase inhibitor GS-9450 induced a significant reduction in ALT level in NASH patients. ${ }^{134}$ PF-03491390 treatment significantly diminished serum AST and ALT levels in patients with chronic HCV infection. ${ }^{135}$ When IDN-6556 was administered in cold storage and flush solutions, the IDN-6556 could provide local therapeutic protection against cold ischemia/warm reperfusion ( $\mathrm{Cl} / \mathrm{WR}$ )-mediated apoptotic injury during liver transplantation. ${ }^{136}$ Oral IDN-6556 considerably lowered aminotransferase activity in HCV patients. ${ }^{137}$ miRNAs have recently been found to represent another crucial regulatory layer overlaying and intersecting with transcriptional control mechanisms. The expression of miR-34a was markedly increased in alcohol-exposed liver or human primary hepatocytes. ${ }^{138}$ miR-122 level correlated with scale of serum lipids in 
NAFLD patients. In both HCV infection and NAFLD patient groups, serum levels of miR-122 and miR-34a correlated with liver enzyme levels, fibrosis stage, and inflammation activity. ${ }^{96}$

In summary, apoptosis has been obviously recognized as a prominent pathogenesis of liver diseases. Full details of apoptosis-related signaling network need to be clarified in future study. Especially, profiles of apoptotic/antiapoptotic regulatory targets and clinical use of these targets will be explored. The study on hepatic apoptosis can develop novel approaches for the treatment of liver diseases.

\section{Conflict of Interest}

The author declares no conflict of interest.

Acknowledgements. I thank UIC Research Open Access Article Publishing (ROAAP) Fund for financial support toward the open access publishing.

1. Smith PG, Tee LB, Yeoh GC. Appearance of oval cells in the liver of rats after long-term exposure to ethanol. Hepatology 1996; 23: 145-154.

2. Sun $C$, Jin XL, Xiao JC. Oval cells in hepatitis B virus-positive and hepatitis $C$ virus-positive liver cirrhosis: histological and ultrastructural study. Histopathology 2006; 48: $546-555$.

3. Soden JS, Devereaux MW, Haas JE, Gumpricht E, Dahl R, Gralla J et al. Subcutaneous vitamin $\mathrm{E}$ ameliorates liver injury in an in vivo model of steatocholestasis. Hepatology 2007; 46: 485-495

4. Dahl TB, Haukeland JW, Yndestad A, Ranheim T, Gladhaug IP, Damas JK et al. Intracellular nicotinamide phosphoribosyltransferase protects against hepatocyte apoptosis and is down-regulated in nonalcoholic fatty liver disease. J Clin Endocrinol Metab 2010; 95: 3039-3047.

5. Waldhauser KM, Torok M, Ha HR, Thomet U, Konrad D, Brecht K et al. Hepatocellular toxicity and pharmacological effect of amiodarone and amiodarone derivatives. J Pharmacol Exp Ther 2006; 319: 1413-1423.

6. Kopycinska J, Kempinska-Podhorodecka A, Haas T, Elias E, DePinho RA, Paik J et al. Activation of FoxO3a/Bim axis in patients with Primary Biliary Cirrhosis. Liver Int 2013; 33: 231-238.

7. Voruganti VS, Cole SA, Ebbesson SO, Goring HH, Haack K, Laston S et al. Genetic variation in APOJ, LPL, and TNFRSF10B affects plasma fatty acid distribution in Alaskan Eskimos. Am J Clin Nutr 2010; 91: 1574-1583.

8. Neuman MG, Cameron RG, Haber JA, Katz GG, Malkiewicz IM, Shear NH. Inducers of cytochrome P450 2E1 enhance methotrexate-induced hepatocytoxicity. Clin Biochem 1999; 32: 519-536.

9. Haake AR, Roublevskaia I, Cooklis M. Apoptosis: a role in skin aging? J Invest Dermatol Symp Proc 1998; 3: 28-35.

10. Haanen C, Vermes I. Apoptosis: programmed cell death in fetal development. Eur J Obstet Gynecol Reprod Biol 1996; 64: 129-133.

11. Kim KW, Ha KY, Lee JS, Rhyu KW, An HS, Woo YK. The apoptotic effects of oxidative stress and antiapoptotic effects of caspase inhibitors on rat notochordal cells. Spine (Phila Pa 1976) 2007; 32: 2443-2448.

12. Haanen C, Vermes I. Apoptosis and inflammation. Mediators Inflamm 1995; 4: 5-15.

13. Cho GW, Shin SM, Kim HK, Ha SA, Kim S, Yoon JH et al. HCCR-1, a novel oncogene, encodes a mitochondrial outer membrane protein and suppresses the UVC-induced apoptosis. BMC Cell Biol 2007; 8: 50.

14. Sadagopal S, Lorey SL, Barnett L, Sutherland D, Basham R, Erdem $\mathrm{H}$ et al. Enhanced $\mathrm{PD}-1$ expression by $T$ cells in cerebrospinal fluid does not reflect functional exhaustion during chronic human immunodeficiency virus type 1 infection. J Virol 2010; 84: 131-140.

15. Gallegos-Orozco JF, Rakela-Brodner J. Hepatitis viruses: not always what it seems to be. Rev Med Chil 2010; 138: 1302-1311.

16. Svirtlih N, Delic D, Simonovic J, Dokic L, Gvozdenovic E, Dulovic $O$ et al. Characteristics of patients dying from acute viral hepatitis in Serbia. Turk J Gastroenterol 2011; 22: 152-157.

17. Lin AW, Gonzalez SA, Cunningham-Rundles S, Dorante G, Marshall S, Tignor A et al. CD56 ( + dim) and CD56 (+ bright) cell activation and apoptosis in hepatitis C virus infection. Clin Exp Immunol 2004; 137: 408-416.

18. Raziorrouh B, Schraut W, Gerlach T, Nowack D, Gruner NH, Ulsenheimer A et al. The immunoregulatory role of CD244 in chronic hepatitis B infection and its inhibitory potential on virus-specific CD8 + T-cell function. Hepatology 2010; 52: 1934-1947.

19. Kohaar I, Ploss A, Korol E, Mu K, Schoggins JW, O'Brien TR et al. Splicing diversity of the human OCLN gene and its biological significance for hepatitis C virus entry. J Virol 2010; 84: $6987-6994$
20. Bekker V, Chanock SJ, Yeager M, Hutchinson AA, von Hahn T, Chen S et al. Genetic variation in CLDN1 and susceptibility to hepatitis C virus infection. J Viral Hepat 2010; 17 192-200.

21. Flint M, Quinn ER, Levy S. In search of hepatitis C virus receptor(s). Clin Liver Dis 2001; 5: 873-893.

22. Germi R, Crance JM, Garin D, Guimet J, Lortat-Jacob H, Ruigrok RW et al. Cellular glycosaminoglycans and low density lipoprotein receptor are involved in hepatitis $\mathrm{C}$ virus adsorption. J Med Virol 2002; 68: 206-215.

23. Schvoerer E, Moenne-Loccoz R, Murray JM, Velay A, Turek M, Fofana I et al. Hepatitis C virus envelope glycoprotein signatures are associated with treatment failure and modulation of viral entry and neutralization. J Infect Dis 2013; 207: 1306-1315.

24. Ploss A, Evans MJ, Gaysinskaya VA, Panis M, You H, de Jong YP et al. Human occludin is a hepatitis $C$ virus entry factor required for infection of mouse cells. Nature 2009; 457 882-886.

25. Wong-Staal F, Syder AJ, McKelvy JF. Targeting HCV entry for development of therapeutics. Viruses 2010; 2: 1718-1733.

26. Reynolds GM, Harris HJ, Jennings A, Hu K, Grove J, Lalor PF et al. Hepatitis C virus receptor expression in normal and diseased liver tissue. Hepatology 2008; 47 418-427.

27. Barrett S, Collins M, Kenny C, Ryan E, Keane CO, Crowe J. Polymorphisms in tumour necrosis factor-alpha, transforming growth factor-beta, interleukin-10, interleukin-6, interferon-gamma, and outcome of hepatitis C virus infection. J Med Virol 2003; 71: 212-218.

28. Abbas Z, Moatter T, Hussainy A, Jafri W. Effect of cytokine gene polymorphism on histological activity index, viral load and response to treatment in patients with chronic hepatitis C genotype 3. World J Gastroenterol 2005; 11: 6656-6661.

29. Ben-Ari Z, Pappo O, Druzd T, Sulkes J, Klein T, Samra Z et al. Role of cytokine gene polymorphism and hepatic transforming growth factor beta1 expression in recurrent hepatitis $C$ after liver transplantation. Cytokine 2004; 27: 7-14.

30. Apolinario A, Majano PL, Alvarez-Perez E, Saez A, Lozano C, Vargas J et al. Increased expression of $\mathrm{T}$ cell chemokines and their receptors in chronic hepatitis $\mathrm{C}$ : relationship with the histological activity of liver disease. Am J Gastroenterol 2002; 97: 2861-2870.

31. Moreno C, Gustot T, Nicaise C, Quertinmont E, Nagy N, Parmentier M et al. CCR5 deficiency exacerbates T-cell-mediated hepatitis in mice. Hepatology 2005; 42: 854-862.

32. Hayashi N, Higashi H, Kaminaka K, Sugimoto H, Esumi M, Komatsu K et al. Molecular cloning and heterogeneity of the human hepatitis $\mathrm{C}$ virus (HCV) genome. J Hepatol 1993; 17(Suppl 3): S94-S107.

33. Kato N. Genome of human hepatitis $\mathrm{C}$ virus (HCV): gene organization, sequence diversity, and variation. Microb Comp Genomics 2000; 5: 129-151.

34. Nam JH, Bukh J, Purcell RH, Emerson SU. High-level expression of hepatitis C virus (HCV) structural proteins by a chimeric HCV/BVDV genome propagated as a BVDV pseudotype. J Virol Methods 2001; 97: 113-123.

35. Zhu N, Ware CF, Lai MM. Hepatitis C virus core protein enhances FADD-mediated apoptosis and suppresses TRADD signaling of tumor necrosis factor receptor. Virology 2001; 283: 178-187.

36. Rubbia-Brandt L, Taylor S, Gindre P, Quadri R, Abid K, Spahr L et al. Lack of in vivo blockade of Fas- and TNFR1-mediated hepatocyte apoptosis by the hepatitis $\mathrm{C}$ virus. J Pathol 2002; 197: 617-623.

37. Prikhod'ko EA, Prikhod'ko GG, Siegel RM, Thompson P, Major ME, Cohen JI. The NS3 protein of hepatitis $C$ virus induces caspase-8-mediated apoptosis independent of its protease or helicase activities. Virology 2004; 329: 53-67.

38. Iken K, Huang L, Bekele H, Schmidt EV, Koziel MJ. Apoptosis of activated CD4 + and $\mathrm{CD} 8+\mathrm{T}$ cells is enhanced by co-culture with hepatocytes expressing hepatitis $\mathrm{C}$ virus (HCV) structural proteins through FasL induction. Virology 2006; 346: 363-372.

39. Pianko S, Patella S, Ostapowicz G, Desmond P, Sievert W. Fas-mediated hepatocyte apoptosis is increased by hepatitis $\mathrm{C}$ virus infection and alcohol consumption, and may be associated with hepatic fibrosis: mechanisms of liver cell injury in chronic hepatitis $\mathrm{C}$ virus infection. J Viral Hepat 2001; 8: 406-413.

40. Valva P, De Matteo E, Galoppo MC, Gismondi MI, Preciado MV. Apoptosis markers related to pathogenesis of pediatric chronic hepatitis $C$ virus infection: M30 mirrors the severity of steatosis. J Med Virol 2010; 82: 949-957.

41. Lam W, Li Y, Liou JY, Dutschman GE, Cheng YC. Reverse transcriptase activity of hepatitis B virus (HBV) DNA polymerase within core capsid: interaction with deoxynucleoside triphosphates and anti-HBV L-deoxynucleoside analog triphosphates. Mol Pharmacol 2004; 65: 400-406.

42. Chen YL, Yu CK, Lei HY. Propionibacterium acnes induces acute TNFalpha-mediated apoptosis of hepatocytes followed by inflammatory T-cell-mediated granulomatous hepatitis in mice. J Biomed Sci 1999; 6: 349-356.

43. Feitelson MA, Reis HM, Tufan NL, Sun B, Pan J, Lian Z. Putative roles of hepatitis B X antigen in the pathogenesis of chronic liver disease. Cancer Lett 2009; 286: 69-79.

44. Peppa D, Gill US, Reynolds G, Easom NJ, Pallett LJ, Schurich A et al. Up-regulation of a death receptor renders antiviral T cells susceptible to NK cell-mediated deletion $J$ Exp Med 2013; 210: 99-114.

45. Liang X, Liu Y, Zhang Q, Gao L, Han L, Ma C et al. Hepatitis B virus sensitizes hepatocytes to TRAIL-induced apoptosis through Bax. J Immunol 2007; 178: 503-510. 
46. Du J, Liang X, Liu Y, Qu Z, Gao L, Han L et al. Hepatitis B virus core protein inhibits TRAIL-induced apoptosis of hepatocytes by blocking DR5 expression. Cell Death Differ 2009; 16: 219-229.

47. Arzumanyan A, Reis HM, Feitelson MA. Pathogenic mechanisms in HBV- and HCV-associated hepatocellular carcinoma. Nat Rev Cancer 2012; 13: 123-135.

48. Woo GA, O'Brien C. Long-term management of alcoholic liver disease. Clin Liver Dis 2012; 16: 763-781.

49. Conde de la Rosa L, Moshage $\mathrm{H}$, Nieto N. [Hepatocyte oxidant stress and alcoholic liver disease]. Rev Esp Enferm Dig 2008; 100: 156-163.

50. Cho EY, Yun $\mathrm{CH}$, Chae HZ, Chae HJ, Ahn T. Anionic phospholipid-induced regulation of reactive oxygen species production by human cytochrome P450 2E1. FEBS Lett 2008; 582: 1771-1776.

51. Gut I, Nedelcheva V, Soucek P, Stopka P, Tichavska B. Cytochromes P450 in benzene metabolism and involvement of their metabolites and reactive oxygen species in toxicity. Environ Health perspect 1996; 104(Suppl 6): 1211-1218

52. Cederbaum Al. Microsomal generation of reactive oxygen species and their possible role in alcohol hepatotoxicity. Alcohol Alcohol Suppl 1991; 1: 291-296.

53. Longato L, Ripp K, Setshedi M, Dostalek M, Akhlaghi F, Branda M et al. Insulin resistance, ceramide accumulation, and endoplasmic reticulum stress in human chronic alcohol-related liver disease. Oxid Med Cell Longev 2012; 2012: 479348

54. Chen P, Tu X, Akdemir F, Chew SK, Rothenfluh A, Abrams JM. Effectors of alcohol-induced cell killing in Drosophila. Cell Death Differ 2012; 19: 1655-1663.

55. Casey CA, Lee SM, Aziz-Seible R, McVicker BL. Impaired receptor-mediated endocytosis: its role in alcohol-induced apoptosis. J Gastroenterol Hepatol 2008; 23(Suppl 1): S46-S49.

56. Dai LL, Gong JP, Zuo GQ, Wu CX, Shi YJ, Li XH et al. Synthesis of endotoxin receptor CD14 protein in Kupffer cells and its role in alcohol-induced liver disease. World $J$ Gastroenterol 2003; 9: 622-626.

57. Purohit V, Brenner DA. Mechanisms of alcohol-induced hepatic fibrosis: a summary of the Ron Thurman Symposium. Hepatology 2006; 43: 872-878.

58. Mu YP, Ogawa T, Kawada N. Reversibility of fibrosis, inflammation, and endoplasmic reticulum stress in the liver of rats fed a methionine-choline-deficient diet. Lab Invest 2010; 90: 245-256.

59. Davit-Spraul A, Gonzales E, Baussan C, Jacquemin E. Progressive familial intrahepatic cholestasis. Orphanet J Rare Dis 2009; 4: 1.

60. Rodriguez-Garay EA. Cholestasis: human disease and experimental animal models. Ann Hepatol 2003; 2: 150-158.

61. Miyoshi H, Rust C, Roberts PJ, Burgart LJ, Gores GJ. Hepatocyte apoptosis after bile duct ligation in the mouse involves Fas. Gastroenterology 1999; 117: 669-677.

62. Schattenberg JM, Zimmermann T, Worns M, Sprinzl MF, Kreft A, Kohl T et al. Ablation of c-FLIP in hepatocytes enhances death-receptor mediated apoptosis and toxic liver injury in vivo. J Hepatol 2011; 55: 1272-1280.

63. Tiao MM, Lin TK, Liou CW, Wang PW, Chen JB, Kuo FY et al. Early transcriptional deregulation of hepatic mitochondrial biogenesis and its consequent effects on murine cholestatic liver injury. Apoptosis 2009; 14: 890-899

64. Faubion WA, Guicciardi ME, Miyoshi H, Bronk SF, Roberts PJ, Svingen PA et al. Toxic bile salts induce rodent hepatocyte apoptosis via direct activation of Fas. J Clin Invest 1999; 103: 137-145

65. Scott FL, Stec B, Pop C, Dobaczewska MK, Lee JJ, Monosov E et al. The Fas-FADD death domain complex structure unravels signalling by receptor clustering. Nature 2009 457: $1019-1022$

66. Hatano E. Tumor necrosis factor signaling in hepatocyte apoptosis. J Gastroenterol Hepatol 2007; 22(Suppl 1): S43-S44.

67. Sodeman T, Bronk SF, Roberts PJ, Miyoshi H, Gores GJ. Bile salts mediate hepatocyte apoptosis by increasing cell surface trafficking of Fas. Am J Physiol Gastrointest Liver Physiol 2000; 278: G992-G999.

68. Gabele E, Froh M, Arteel GE, Uesugi T, Hellerbrand C, Scholmerich J et al. TNFalpha is required for cholestasis-induced liver fibrosis in the mouse. Biochem Biophys Res Commun 2009; 378: 348-353.

69. Higuchi H, Bronk SF, Takikawa Y, Werneburg N, Takimoto R, El-Deiry W et al. The bile acid glycochenodeoxycholate induces trail-receptor 2/DR5 expression and apoptosis. J Biol Chem 2001; 276: 38610-38618.

70. Takeda K, Kojima Y, Ikejima K, Harada K, Yamashina S, Okumura K et al. Death receptor 5 mediated-apoptosis contributes to cholestatic liver disease. Proc Natl Acad Sci USA 2008; 105: 10895-10900.

71. Aktas C, Kanter M, Erboga M, Mete R, Oran M. Melatonin attenuates oxidative stress, liver damage and hepatocyte apoptosis after bile-duct ligation in rats. Toxicol Ind Health 2012; e-pub ahead of print 24 October 2012; doi:10.1177/0748233712464811.

72. Welge-Lussen $U$, May CA, Lutjen-Drecoll E. Induction of tissue transglutaminase in the trabecular meshwork by TGF-beta1 and TGF-beta2. Invest Ophthalmol Vis Sci 2000; 41: 2229-2238.

73. Ghatak S, Biswas A, Dhali GK, Chowdhury A, Boyer JL, Santra A. Oxidative stress and hepatic stellate cell activation are key events in arsenic induced liver fibrosis in mice. Toxicol Appl Pharmacol 2011; 251: 59-69.

74. Rodrigues CM, Fan G, Wong PY, Kren BT, Steer CJ. Ursodeoxycholic acid may inhibit deoxycholic acid-induced apoptosis by modulating mitochondrial transmembrane potential and reactive oxygen species production. Mol Med 1998; 4: 165-178.
75. Roma MG, Toledo FD, Boaglio AC, Basiglio CL, Crocenzi FA, Sanchez Pozzi EJ. Ursodeoxycholic acid in cholestasis: linking action mechanisms to therapeutic applications. Clin Sci (Lond) 2011; 121: 523-544.

76. Wang K, Holterman AX. Pathophysiologic role of hepatocyte nuclear factor 6 . Cell Signal 2012; 24: 9-16.

77. Serfaty L, Lemoine M. Definition and natural history of metabolic steatosis: clinical aspects of NAFLD, NASH and cirrhosis. Diab Metab 2008; 34(6 Pt 2): 634-637.

78. Brunt EM, Kleiner DE, Wilson LA, Unalp A, Behling CE, Lavine JE et al. Portal chronic inflammation in nonalcoholic fatty liver disease (NAFLD): a histologic marker of advanced NAFLD-Clinicopathologic correlations from the nonalcoholic steatohepatitis clinical research network. Hepatology 2009; 49: 809-820.

79. Bhala N, Jouness RI, Bugianesi E. Epidemiology and natural history of patients with NAFLD. Curr Pharm Des 2013; 19: 5169-5176.

80. Hirosumi J, Tuncman G, Chang L, Gorgun CZ, Uysal KT, Maeda K et al. A central role for JNK in obesity and insulin resistance. Nature 2002; 420: 333-336.

81. Vallerie SN, Furuhashi M, Fucho R, Hotamisligil GS. A predominant role for parenchymal c-Jun amino terminal kinase (JNK) in the regulation of systemic insulin sensitivity. PLoS One 2008; 3: e3151.

82. Coulon S, Francque S, Colle I, Verrijken A, Blomme B, Heindryckx F et al. Evaluation of inflammatory and angiogenic factors in patients with non-alcoholic fatty liver disease. Cytokine 2012; 59: 442-449.

83. Yu HY, Wang BL, Zhao J, Yao XM, Gu Y, Li Y. Protective effect of bicyclol on tetracyclineinduced fatty liver in mice. Toxicology 2009; 261: 112-118.

84. Park JW, Jeong G, Kim SJ, Kim MK, Park SM. Predictors reflecting the pathological severity of non-alcoholic fatty liver disease: comprehensive study of clinical and immunohistochemical findings in younger Asian patients. J Gastroenterol Hepatol 2007; 22: 491-497.

85. Wree A, Kahraman A, Gerken G, Canbay A. Obesity affects the liver-the link between adipocytes and hepatocytes. Digestion 2011; 83: 124-133.

86. Bechmann LP, Kocabayoglu P, Sowa JP, Sydor S, Best J, Schlattjan M et al. Free fatty acids repress SHP activation and adiponectin counteracts bile acid induced liver injury in super-obese patients with NASH. Hepatology 2013; 57: 1394-1406.

87. Malhi H, Barreyro FJ, Isomoto $\mathrm{H}$, Bronk SF, Gores GJ. Free fatty acids sensitise hepatocytes to TRAIL mediated cytotoxicity. Gut 2007; 56: 1124-1131.

88. Malhi H, Bronk SF, Werneburg NW, Gores GJ. Free fatty acids induce JNK-dependent hepatocyte lipoapoptosis. J Biol Chem 2006; 281: 12093-12101.

89. Moschen AR, Wieser V, Tilg H. Adiponectin: key player in the adipose tissue-liver crosstalk. Curr Med Chem 2012; 19: 5467-5473.

90. Zheng H, Li S, Ma L, Cheng L, Deng C, Chen Z et al. A novel agonist of PPAR-gamma based on barbituric acid alleviates the development of non-alcoholic fatty liver disease by regulating adipocytokine expression and preventing insulin resistance. Eur J Pharmacol 2011; 659: 244-251

91. Benhamed F, Denechaud PD, Lemoine M, Robichon C, Moldes M, Bertrand-Michel J et al. The lipogenic transcription factor ChREBP dissociates hepatic steatosis from insulin resistance in mice and humans. J Clin Invest 2012; 122: 2176-2194.

92. Kohjima M, Higuchi N, Kato M, Kotoh K, Yoshimoto T, Fujino $T$ et al. SREBP-1c, regulated by the insulin and AMPK signaling pathways, plays a role in nonalcoholic fatty liver disease. Int J Mol Med 2008; 21: 507-511.

93. Guzman C, Benet M, Pisonero-Vaquero S, Moya M, Garcia-Mediavilla MV Martinez-Chantar ML et al. The human liver fatty acid binding protein (FABP1) gene is activated by FOXA1 and PPARalpha; and repressed by C/EBPalpha: Implications in FABP1 down-regulation in nonalcoholic fatty liver disease. Biochim Biophys Acta 2013; 1831: 803-818.

94. Rottiers V, Naar AM. MicroRNAs in metabolism and metabolic disorders. Nat Rev Mol Cell Biol 2012; 13: 239-250.

95. Sharma $\mathrm{H}$, Estep M, Birerdinc A, Afendy A, Moazzez A, Elariny $\mathrm{H}$ et al. Expression of genes for microRNA-processing enzymes is altered in advanced non-alcoholic fatty liver disease. J Gastroenterol Hepatol 2013; 28: 1410-1415.

96. Cermelli S, Ruggieri A, Marrero JA, loannou GN, Beretta L. Circulating microRNAs in patients with chronic hepatitis $C$ and non-alcoholic fatty liver disease. PLoS One 2011; 6: e23937.

97. Castro RE, Ferreira DM, Afonso MB, Borralho PM, Machado MV, Cortez-Pinto $\mathrm{H}$ et al. miR-34a/SIRT1/p53 is suppressed by ursodeoxycholic acid in the rat liver and activated by disease severity in human non-alcoholic fatty liver disease. $J$ Hepatol 2013; 58 : $119-125$

98. Cazanave SC, Mott JL, Elmi NA, Bronk SF, Masuoka HC, Charlton MR et al. A role for miR-296 in the regulation of lipoapoptosis by targeting PUMA. J Lipid Res 2011; 52: $1517-1525$.

99. Bjornsson ES, Bergmann OM, Bjornsson HK, Kvaran RB, Olafsson S. Incidence, presentation and outcomes in patients with drug-induced liver injury in the general population of Iceland. Gastroenterology 2013; 144: 1419-1425.

100. Lucena MI, Garcia-Martin E, Andrade RJ, Martinez C, Stephens C, Ruiz JD et al. Mitochondrial superoxide dismutase and glutathione peroxidase in idiosyncratic drug-induced liver injury. Hepatology 2010; 52: 303-312.

101. von Felden J, Montani M, Kessebohm K, Stickel F. Drug-induced acute liver injury mimicking autoimmune hepatitis after intake of dietary supplements containing glucosamine and chondroitin sulfate. Int J Clin Pharmacol Ther 2013; 51: 219-223. 
102. Tanaka Y, Takahashi A, Watanabe K, Takayama K, Yahata T, Habu S et al. A pivotal role of IL-12 in Th1-dependent mouse liver injury. Int Immunol 1996; 8: 569-576.

103. Nanji AA, Jokelainen $K$, Rahemtulla A, Miao L, Fogt $F$, Matsumoto $H$ et al. Activation of nuclear factor kappa $\mathrm{B}$ and cytokine imbalance in experimental alcoholic liver disease in the rat. Hepatology 1999; 30: 934-943.

104. Rowell DL, Eckmann L, Dwinell MB, Carpenter SP, Raucy JL, Yang SK et al. Human hepatocytes express an array of proinflammatory cytokines after agonist stimulation or bacterial invasion. Am J Physiol 1997; 273(2 Pt 1): G322-G332.

105. Li M, Liu GT. Inhibition of Fas/FasL mRNA expression and TNF-alpha release in concanavalin A-induced liver injury in mice by bicyclol. World J Gastroenterol 2004; 10: 1775-1779.

106. Huang J, Shi W, Zhang J, Chou JW, Paules RS, Gerrish K et al. Genomic indicators in the blood predict drug-induced liver injury. Pharmacogenomics J 2010; 10: 267-277.

107. Cavassani KA, Moreira AP, Habiel D, Ito T, Coelho AL, Allen RM et al. Toll like receptor 3 plays a critical role in the progression and severity of acetaminophen-induced hepatotoxicity. PLoS One 2013; 8: e65899.

108. Badmann A, Keough A, Kaufmann T, Bouillet P, Brunner T, Corazza N. Role of TRAIL and the pro-apoptotic Bcl-2 homolog Bim in acetaminophen-induced liver damage. Cell Death Dis 2011; 2: e171.

109. Badmann A, Langsch S, Keogh A, Brunner T, Kaufmann T, Corazza N. TRAIL enhances paracetamol-induced liver sinusoidal endothelial cell death in a Bim- and Bid-dependent manner. Cell Death Dis 2012; 3: e447.

110. Lee WM, Senior JR. Recognizing drug-induced liver injury: current problems, possible solutions. Toxicol Pathol 2005; 33: 155-164.

111. Roth GA, Krenn C, Brunner M, Moser B, Ploder M, Spittler A et al. Elevated serum levels of epithelial cell apoptosis-specific cytokeratin 18 neoepitope $\mathrm{m} 30$ in critically ill patients. Shock 2004; 22: 218-220.

112. Han D, Shinohara M, Ybanez MD, Saberi B, Kaplowitz N. Signal transduction pathways involved in drug-induced liver injury. Handb Exp Pharmacol 2010; 196: 267-310.

113. Ghavami S, Hashemi M, Kadkhoda K, Alavian SM, Bay GH, Los M. Apoptosis in liver diseases-detection and therapeutic applications. Med Sci Monit 2005; 11: RA337-RA345

114. Santodomingo-Garzon T, Swain MG. Role of NKT cells in autoimmune liver disease. Autoimmun Rev 2011; 10: 793-800.

115. Selmi C, Mackay IR, Gershwin ME. The autoimmunity of primary biliary cirrhosis and the clonal selection theory. Immunol Cell Biol 2011; 89: 70-80.

116. Mao TK, Davis PA, Odin JA, Coppel RL, Gershwin ME. Sidechain biology and the immunogenicity of PDC-E2, the major autoantigen of primary biliary cirrhosis. Hepatology 2004; 40: 1241-1248

117. Allina J, Hu B, Sullivan DM, Fiel MI, Thung SN, Bronk SF et al. T cell targeting and phagocytosis of apoptotic biliary epithelial cells in primary biliary cirrhosis. J Autoimmun 2006; 27: 232-241.

118. Floreani A, Zancan L, Melis A, Baragiotta A, Chiaramonte M. Primary sclerosing cholangitis (PSC): clinical, laboratory and survival analysis in children and adults. Liver 1999; 19: 228-233.

119. Rudolph G, Gotthardt D, Kloeters-Plachky P, Rost D, Kulaksiz H, Stiehl A. In PSC with dominant bile duct stenosis, IBD is associated with an increase of carcinomas and reduced survival. J Hepatol 2010; 53: 313-317.

120. Bernstein $\mathrm{CN}$. Osteoporosis and other complications of inflammatory bowel disease. Curr Opin Gastroenterol 2002; 18: 428-434.

121. Broome U, Glaumann H, Lindstom E, Loof L, Almer S, Prytz H et al. Natural history and outcome in 32 Swedish patients with small duct primary sclerosing cholangitis (PSC). $J$ Hepatol 2002; 36: 586-589

122. Kremer AE, Rust $\mathrm{C}$, Eichhorn $\mathrm{P}$, Beuers $\mathrm{U}$, Holdenrieder $\mathrm{S}$. Immune-mediated liver diseases: programmed cell death ligands and circulating apoptotic markers. Exp Rev Mol Diagn 2009; 9: 139-156.
123. Gantner F, Leist M, Lohse AW, Germann PG, Tiegs G. Concanavalin A-induced T-cell-mediated hepatic injury in mice: the role of tumor necrosis factor. Hepatology 1995; 21: $190-198$.

124. Volarevic V, Milovanovic M, Ljujic B, Pejnovic N, Arsenijevic N, Nilsson U et al. Galectin-3 deficiency prevents concanavalin A-induced hepatitis in mice. Hepatology 2012; 55 1954-1964.

125. Kim KM, Kim YM, Park M, Park K, Chang HK, Park TK et al. A broad-spectrum caspase inhibitor blocks concanavalin A-induced hepatitis in mice. Clin Immunol 2000; 97 221-233.

126. Ding JW, Wang K, Brems JJ, Gamelli RL. Protection against concanavalin A-induced hepatocyte apoptosis by molsidomine is time-dependent. J Am Coll Surg 2004; 198: 67-77.

127. Zhang $\mathrm{H}$, Gong $\mathrm{Q}$, Li JH, Kong XL, Tian L, Duan LH et al. CpG ODN pretreatment attenuates concanavalin A-induced hepatitis in mice. Int Immunopharmacol 2010; 10 $79-85$.

128. Jouan-Lanhouet S, Arshad MI, Piquet-Pellorce C, Martin-Chouly C, Le Moigne-Muller G Van Herreweghe $\mathrm{F}$ et al. TRAIL induces necroptosis involving RIPK1/RIPK3-dependent PARP-1 activation. Cell Death Differ 2012; 19: 2003-2014.

129. Wen YA, Liu D, Zhou QY, Huang SF, Luo $P$, Xiang $Y$ et al. Biliary intervention aggravates cholestatic liver injury, and induces hepatic inflammation, proliferation and fibrogenesis in BDL mice. Exp Toxicol Pathol 2011; 63: 277-284.

130. Kaiser WJ, Upton JW, Long AB, Livingston-Rosanoff D, Daley-Bauer LP, Hakem R et al. RIP3 mediates the embryonic lethality of caspase-8-deficient mice. Nature 2011; 471 368-372.

131. Liedtke C, Bangen JM, Freimuth J, Beraza N, Lambertz D, Cubero FJ et al. Loss of caspase-8 protects mice against inflammation-related hepatocarcinogenesis but induces non-apoptotic liver injury. Gastroenterology 2011; 141: 2176-2187.

132. Hikita H, Takehara T, Shimizu S, Kodama T, Li W, Miyagi T et al. Mcl-1 and Bcl-xL cooperatively maintain integrity of hepatocytes in developing and adult murine liver. Hepatology 2009; 50: 1217-1226.

133. Vick B, Weber A, Urbanik T, Maass T, Teufel A, Krammer PH et al. Knockout of myeloid cell leukemia-1 induces liver damage and increases apoptosis susceptibility of murine hepatocytes. Hepatology 2009; 49: 627-636.

134. Ratziu V, Sheikh MY, Sanyal AJ, Lim JK, Conjeevaram H, Chalasani N et al. A phase 2 randomized, double-blind, placebo-controlled study of GS-9450 in subjects with nonalcoholic steatohepatitis. Hepatology 2012; 55: 419-428.

135. Shiffman ML, Pockros P. McHutchison JG, Schiff ER, Morris M, Burgess G. Clinical trial: the efficacy and safety of oral PF-03491390, a pancaspase inhibitor-a randomized placebo-controlled study in patients with chronic hepatitis C. Aliment Pharmacol Ther 2010; 31: 969-978.

136. Baskin-Bey ES, Washburn K, Feng S, Oltersdorf T, Shapiro D, Huyghe M et al. Clinical trial of the pan-caspase inhibitor, IDN-6556, in human liver preservation injury. Am J Transplant 2007; 7: 218-225.

137. Pockros PJ, Schiff ER, Shiffman ML, McHutchison JG, Gish RG, Afdhal NH et al. Oral IDN-6556, an antiapoptotic caspase inhibitor, may lower aminotransferase activity in patients with chronic hepatitis C. Hepatology 2007; 46: 324-329.

138. Meng F, Glaser SS, Francis H, Yang F, Han Y, Stokes A et al. Epigenetic regulation of miR-34a expression in alcoholic liver injury. Am $J$ Pathol 2012; 181: 804-817.

(1) () $\Theta$ Cell Death and Disease is an open-access journal By ${ }^{2}$ po published by Nature Publishing Group. This work is licensed under the Creative Commons Attribution-NonCommercial-No Derivative Works 3.0 Unported License. To view a copy of this license, visit http://creativecommons.org/licenses/by-nc-nd/3.0/ 